\title{
Confirmatory factor analysis model of factors affecting the implementation of clinical guidelines in Iran
}

\author{
Farzaneh Kimiaeimehr ${ }^{1}$, Seyed Mojtaba Hosseini*1 (D) Khalil Alimohammadzadeh ${ }^{1,2}$, Mohammadkarim Bahadori ${ }^{3}$, \\ Ali Maher 4,1
}

Received: 18 May 2019

Published: 16 Sep 2020

\begin{abstract}
Background: Clinical guidelines refer to a developed scientific statement to help physicians and patients for decision-making about the best care for special clinical conditions, which can be an important document to shape evidence-based medicine. This study aimed to identify factors affecting the implementation of clinical guidelines in Iran to enhance the quality of services.

Methods: This descriptive analytical study was performed with combined quantitative-qualitative method in the first half of 2019. The statistical population consisted of 400 health managers and experts who were selected through multistage sampling method in 5 regions of Iran (north, south, center, east, and west). Overall, 20 academic experts were selected from each university. For data collection, a researcher-made questionnaire $(n=400)$ was used. To measure face and content validity, content validity ratio $(C V R)$ and content validity index (CVI) were used. Also, to determine reliability, test-retest method, with Cronbach's alpha coefficient of 0.934 was used. For data analysis, Lisrel 8.8 and SPSS 24 were used. Finally, fitness indices were used to determine the fitness of the model.

Results: Six factors, including organizational (9 components), organizational culture ( 8 components), the clinical guidelines feature ( 8 components), insurance ( 7 components), and trusteeship of the health care system ( 8 components) were identified as the main dimensions. The economic dimension had the maximum effect on implementing clinical guidelines $(0.90)$, while the clinical guidelines feature (0.63) and organizational culture (0.63) showed the minimum extent of effect on implementing clinical guidelines.

Conclusion: Evidently, imposing the mentioned interventions with the ultimate goal of sustainable behavior change in providing health care services requires contribution of all practitioners, presentation of suitable facilities for implementing clinical guidelines based on evidence, time and personnel management, training methodology and planning, developing the necessary infrastructure, supervision, and developing professional and legal motivation.
\end{abstract}

Keywords: Clinical guidelines, Evidence-based medicine, Implementing clinical guidelines, Obstacles, Facilitator

Conflicts of Interest: None declared

Funding: None

*This work has been published under CC BY-NC-SA 1.0 license.

Copyright $₫$ Iran University of Medical Sciences

Cite this article as: Kimiaeimehr F, Hosseini SM, Alimohammadzadeh Kh, Bahadori M, Maher A. Confirmatory factor analysis model of factors affecting the implementation of clinical guidelines in Iran. Med J Islam Repub Iran. 2020 (16 Sep);34:122. https://doi.org/10.47176/mjiri.34.122

\section{Introduction}

The main reason for the different practices in similar health care is the gap between knowledge production and
Corresponding author: Dr Seyed Mojtaba Hosseini, sm_hosseini@iau-tnb.ac.ir

1. Department of Health Services Management, North Tehran Branch, Islamic Azad University, Tehran, Iran

2. Health Economics Policy Research Center, Tehran Medical Sciences Branch, Islamic Azad University, Tehran, Iran

3. Health Management Research Center, Baqiyatallah University of Medical Sciences, Tehran, Iran

4. Department of Health Policy, School of Management and Medical Education, Shahid Beheshti University of Medical Sciences, Tehran, Iran
What is "already known" in this topic:

In previous studies, there is no general model for implementing clinical guidelines in Iran. Also, the factors affecting the implementation of clinical guidelines in Iran have not been identified.

\section{$\rightarrow$ What this article adds:}

This study is the first study for identifying the managerial factors influencing the implementation of clinical guidelines.

In the clinical guideline model, factors affecting the implementation of the guidelines have been identified.

This model helps policymakers and managers in implementing clinical guidelines.

This model provides the context for improving the quality of services provided by health care providers. 
its consequences. Measuring the "gap" between evidence and actual practice or policy-making is one of the first steps in knowledge translation (1). By evidence, we mean the best available research-based evidence (2). Ideally, this evidence should come from high-quality practice guidelines or systematic reviews (3). To fill this gap, in recent years, the evidence-based method has attracted a great deal of attention $(4,5)$. This method is an international priority in an attempt to improve the quality of health care and has been defined as integrating clinical experience with high quality evidence and patient priority $(6,7)$. Clinical guidelines refer to a developed scientific statement to help the patient and physician for decisionmaking about the best care for special clinical conditions, which can be an important document to shape evidencebased medicine $(8,9)$. Development and implementation of instructions aim to organize and present the best available evidence to support clinical decision-making to improve health care quality, outcome of patients, effectiveness, and cost reduction (10-14). Clinical guidelines are categorized and provide information to help the decisionmaking of medical teams, with the aim of improving patients care. Therefore, this study aimed to identify the factors influencing the implementation of clinical guidelines in Iran (15). Accordingly, clinical instructions can help the executors to improve professional performance in hospitals and also enhance the performance level of different groups of health care providers, quality of care, and patients' outcome (16).

In countries, such as USA and the Netherlands, around $30 \%-40 \%$ of patients do not receive evidence that the patients receive the treatments that are not required or are even sometimes harmful. Indeed, there is a gap between what is currently available and the best evidence-based medical treatment (17). Not following instructions may result in inessential diagnosis and inadequate or unfocused treatment (18). The investigation by Wolpert et al in London revealed many obstacles against the use of evidence and its implementation. The major obstacles include lack of time, lack of knowledge, lack of medical resources, negative attitude to evidence, and financial constraints (19). In the investigation by Kabana et al, lack of awareness, limited familiarity, and disagreeing with clinical guidelines were found to be the main obstacles in approving clinical guidelines. Furthermore, this investigation concluded that the main obstacle can be attributed to the simple fact that sometimes physicians are not aware of the existence of special clinical guidelines (16). In addition, the findings of a qualitative study in Iran indicated the obstacles for creating, developing, and implementing clinical guidelines include the context of practice, evidencebased health care systems, professionality of individuals, supportive policymakers and political context, innovation, and patients (20).

A study in Tehran indicated only $31.8 \%$ of physicians were aware of clinical instructions for presenting health care services. The obstacles against implementation, according to these people, included lack of awareness of development of clinical instructions and evidence-based performance $(37 \%)$, being time-consuming and tedious
(70\%), unavailability (60\%), lack of skill of physicians in using clinical guidelines (31\%), and absence of the necessary conditions and facilities (65\%) (21). Furthermore, the authors developed a framework in which these obstacles were categorized into 3 main groups: the obstacles related to physician's knowledge (eg, lack of awareness and unfamiliarity), obstacles affecting the attitude of physicians (eg, absence of agreement and lack of motivation), and external factors (patient-associated factors, the feature of guidelines, and environmental factors) (9, 22, 23). Furthermore, the results obtained from a study in Iran showed $39 \%$ of the participants had very little familiarity with EBM databases and only $12.7 \%$ of these databases were very familiar (24).

The implementation strategies should be based on the current knowledge about effective interventions and evaluating the potential obstacles to approve guidelines (25, 26). Evaluating the obstacles and facilitators to implement clinical instructions is the first step to adapt and approve localized evidence (27). Clinical instructions can improve the quality of health care services, but there are a number of challenges in adopting and implementing the instructions (11). Therefore, given the investigations performed in Iran, there are problems in implementation of the guidelines, including absence of adequate studies about the obstacles of implementation and unavailability of a suitable executive model. Therefore, to motivate the authorities to select development policies and use clinical guidelines, this study aimed to identify factors affecting the implementation of clinical guidelines in Iran.

\section{Methods}

This descriptive analytical study was performed using Mix method that combined quantitative-qualitative method in 2019. The study population was selected from the managers, directors, deputies, and heads of medical universities in Iran, the experts, and middle managers and heads of the medical departments in medical sciences universities. The sample size was 400 and participants were selected by multistage sampling at 5 regions in the country (north, south, east, west and center); in each region with 4 universities and 5 quotas, they were assigned into the clusters. A total of 20 experts were selected from each university.

In this study, information form and questionnaire were used to collect data. In the initial stage, all relevant studies were conducted on the barriers and facilitators, knowledge and attitude, and the impact of factors on the implementation of clinical guidelines in Iran and worldwide by referring to libraries and searching the internet in Persian and non-Persian databases. In the internet search Persian and English keywords were deliberately studied and all relevant factors were extracted by taking notes. An interview was conducted with experts and in the field of formulating clinical guidelines to extract additional information. Then, the initial questionnaire was designed. The first section included gender, age, education level, management history, work place, and field of study. The second section included 47 questions about the factors influencing the implementation of clinical guidelines in dimensions and re- 
lated factors. To ensure the reliability of the questionnaire, the initial sample was selected using the test-retest method by selecting 50 people. Based on the number of evaluators $(\mathrm{n}=20)$, the minimum acceptable value of CVR and CVI was 0.42 and 0.79 , respectively. Also, in the CVR survey, 47 items scored above 0.42 , and the CVI results showed all items received a score above 0.8 . Finally, out of 62 variables of the initial questionnaire, according to the CVR and CVI, 47 variables were finalized. The content validity rate and content validity index for the whole questionnaire were calculated 0.9 and 0.9 . To investigate the validity of the questionnaire, formal validity and content validity were used in 2 quantitative and qualitative methods, including content validity ratio (CVR) and content validity index (CVI) using a 20-person panel. Based on the number of evaluators, the minimum acceptable values of CVR and CVI were 0.42 and more than 0.79 , respectively. The confirmatory factor analysis (CFA) with covariance-based approach was used to verify the fitness of the measuring tool (questionnaire) and Lisrel 8.8 and SPSS 24.0 software. Also, goodness-of -fit indices $\left(\chi^{2} / \mathrm{df}\right.$, RMSEA, NFI, NNFI, CFI, IFI, GFI ) were used to determine pattern fitness. In the present study the following fundamental principles were taken into consideration as the ethical considerations: coordination with the Ministry of Health and Medical Education through an introduction letter, provision of the required explanations of the projects and their objectives to the experts, voluntary participation in the study, so that the participations could withdraw from the study in each stage, anonymous responses to the questionnaire items, and confidential data analysis.

\section{Results}

The results indicated the mean $\pm \mathrm{SD}$ of age in the participants was $40.53 \pm 6.86$ years, with a standard deviation of 6.86 .

\begin{tabular}{|c|c|c|c|c|c|c|}
\hline Sex & Age & Education Level & $\begin{array}{c}\text { Job } \\
\text { Experience }\end{array}$ & $\begin{array}{l}\text { Management } \\
\text { Experience }\end{array}$ & Field of Study & N (\%) \\
\hline Male & & & & & & $230(42.5)$ \\
\hline Female & & & & & & $170(57.5)$ \\
\hline & $<30$ & & & & & $46(11.5)$ \\
\hline & $30-35$ & & & & & $43(10.8)$ \\
\hline & $35-40$ & & & & & $77(19.3)$ \\
\hline & $40-45$ & & & & & $90(22.5)$ \\
\hline & $>45$ & & & & & $144(36)$ \\
\hline & & Master's degree & & & & $69(17.3)$ \\
\hline & & PHD & & & & $76(19)$ \\
\hline & & Public doctorate & & & & $56(14)$ \\
\hline & & Medical expertise & & & & $64(16)$ \\
\hline & & $\begin{array}{c}\text { Super specialist } \\
\text { doctor }\end{array}$ & & & & $118(29.9)$ \\
\hline & & Fellowship & & & & $17(4.3)$ \\
\hline & & & $<5$ & & & $38(9.5)$ \\
\hline & & & $5-10$ & & & $65(16.3)$ \\
\hline & & & $10-15$ & & & $94(23.5)$ \\
\hline & & & $15-20$ & & & $105(26.3)$ \\
\hline & & & $20>$ & & & $98(24.5)$ \\
\hline & & & & $<5$ & & $76(19)$ \\
\hline & & & & $5-10$ & & $128(32)$ \\
\hline & & & & $11-20$ & & $121(30.3)$ \\
\hline & & & & $>20$ & & $75(18.8)$ \\
\hline & & & & & Health care service management & $86(21.5)$ \\
\hline & & & & & Medical & $76(19)$ \\
\hline & & & & & Nursing & $40(10)$ \\
\hline & & & & & Urologist & $20(5)$ \\
\hline & & & & & Internist & $42(10.5)$ \\
\hline & & & & & Specialist of infectious diseases & $2(0 / 5)$ \\
\hline & & & & & Pediatrician & $24(6)$ \\
\hline & & & & & Medical files & $1(0 / 3)$ \\
\hline & & & & & Cardiologist & $14(3.5)$ \\
\hline & & & & & Traditional medicine & $1(0 / 3)$ \\
\hline & & & & & Policymaking & $2(0 / 5)$ \\
\hline & & & & & Emergency specialist & $13(3.3)$ \\
\hline & & & & & Neurologist & $7(1.8)$ \\
\hline & & & & & General surgeon & $5(1.3)$ \\
\hline & & & & & Health economics & $8(2)$ \\
\hline & & & & & Midwifery & $9(2.3)$ \\
\hline & & & & & Medical nutrition & $3(0 / 8)$ \\
\hline & & & & & Gynecologist & $8(2)$ \\
\hline & & & & & ENT specialist & $5(1.3)$ \\
\hline & & & & & Orthopedist & $4(1)$ \\
\hline & & & & & Endocrinologist & $19(4.8)$ \\
\hline & & & & & ocular surgeon & $7(1.8)$ \\
\hline & & & & & Medical education & $4(1)$ \\
\hline
\end{tabular}


The maximum frequency in the variable of gender was related to men with $230(57.5 \%)$ participants, while the maximum frequency regarding the level of education was associated with medical subspecialty with 118 individuals (29.5\%). Considering working experience, the greatest frequency was related to the group with 15-20 years of experience, with a frequency of $105(26.3 \%)$. Also, regarding management background, the maximum frequency was related to the group with 5-10 years of experience, with the frequency of 128 $(32 \%)$. Regarding the field of study, the highest frequency was in the field of health care services management, with a frequency of 86 people (21.5\%) (Table 1).

In the qualitative phase of studying the results of reviewing resources, a 6-dimensional model suggests the following dimensions: organizational (9 components), organizational culture (8 components), the clinical guidelines feature (8 components), insurance (7 components), and trusteeship of the health care system (8 components) (Table 2$)$.

\begin{tabular}{|c|c|c|c|c|c|c|c|c|c|}
\hline Factors & & & & & Components & & & & \\
\hline $\begin{array}{l}\text { Insurance: } \\
\text { B1- B7 }\end{array}$ & $\begin{array}{l}\text { Correcting the } \\
\text { payment system }\end{array}$ & $\begin{array}{l}\text { Aggregating the } \\
\text { resources of insurer } \\
\text { organizations }\end{array}$ & $\begin{array}{l}\text { Optimal and strategic } \\
\text { purchase of services }\end{array}$ & Insurance tariffs & $\begin{array}{l}\text { Supplying financial } \\
\text { resources }\end{array}$ & $\begin{array}{l}\text { Preparing, designing and } \\
\text { developing incentive } \\
\text { packages by } \\
\text { insurers }\end{array}$ & $\begin{array}{l}\text { Integrated function of } \\
\text { insurer organizations }\end{array}$ & & \\
\hline $\begin{array}{l}\text { Healthcare } \\
\text { system } \\
\text { trusteeship: } \\
\text { T1-T8 }\end{array}$ & $\begin{array}{l}\text { The necessity of } \\
\text { integrated healthcare } \\
\text { system }\end{array}$ & $\begin{array}{l}\text { Improving the struc- } \\
\text { ture and resolving the } \\
\text { methodologic prob- } \\
\text { lems of guidelines }\end{array}$ & $\begin{array}{l}\text { Developing regula- } \\
\text { tions and bylaws and } \\
\text { supervising the im- } \\
\text { plementation }\end{array}$ & $\begin{array}{l}\text { Existence of a practical } \\
\text { evidence-based system }\end{array}$ & $\begin{array}{c}\text { Paying attention to } \\
\text { professional features and } \\
\text { the strategy of } \\
\text { implementing instructions }\end{array}$ & $\begin{array}{l}\text { Support of managers and } \\
\text { decision-makers institu- } \\
\text { tions }\end{array}$ & $\begin{array}{l}\text { Time and personnel } \\
\text { management }\end{array}$ & $\begin{array}{l}\text { Resolving simula- } \\
\text { tion in clinical } \\
\text { setting }\end{array}$ & \\
\hline $\begin{array}{l}\text { Economic } \\
\text { factor: } \\
\text { E1-E7 }\end{array}$ & $\begin{array}{l}\text { The necessary } \\
\text { investments for } \\
\text { realizing implementa- } \\
\text { tion of guidelines }\end{array}$ & $\begin{array}{l}\text { Financial profit in the } \\
\text { using clinical } \\
\text { guidelines }\end{array}$ & $\begin{array}{l}\text { Developing the } \\
\text { necessary } \\
\text { infrastructures for } \\
\text { implementing } \\
\text { guidelines }\end{array}$ & $\begin{array}{l}\text { Caring for the cost of } \\
\text { access to evidence }\end{array}$ & $\begin{array}{l}\text { Caring for clinical } \\
\text { uncertainty }\end{array}$ & $\begin{array}{l}\text { Availability of budget } \\
\text { and resolving budget } \\
\text { constraints }\end{array}$ & $\begin{array}{l}\text { Multidimensionality of } \\
\text { health phenomenon }\end{array}$ & & \\
\hline $\begin{array}{l}\text { Organizational } \\
\text { factors: } \\
\text { S1-S }\end{array}$ & $\begin{array}{l}\text { Proper structure of the } \\
\text { organization and } \\
\text { development of the } \\
\text { organization }\end{array}$ & $\begin{array}{l}\text { Interaction and } \\
\text { cooperation in } \\
\text { development sectors } \\
\text { to implement the } \\
\text { clinical guidelines }\end{array}$ & $\begin{array}{l}\text { Holding training } \\
\text { courses in the } \\
\text { academic education } \\
\text { and constant training }\end{array}$ & $\begin{array}{l}\text { Caring for clinical } \\
\text { guidelines in } \\
\text { policymaking under } \\
\text { macro conditions }\end{array}$ & $\begin{array}{l}\text { Developing behavior } \\
\text { adaptation and approving } \\
\text { guidelines in case of } \\
\text { availability of evidence } \\
\text { and the alternative to the } \\
\text { best method }\end{array}$ & $\begin{array}{l}\text { Ability, skill, and } \\
\text { experience employing the } \\
\text { research findings in the } \\
\text { healthcare }\end{array}$ & $\begin{array}{l}\text { Familiarity, developing } \\
\text { motivation, and attempts } \\
\text { for teamwork }\end{array}$ & $\begin{array}{l}\text { Changing the } \\
\text { attitude of } \\
\text { employees to } \\
\text { reliability, im- } \\
\text { portance, and } \\
\text { usefulness of } \\
\text { instructions }\end{array}$ & $\begin{array}{l}\text { Attracting the } \\
\text { cooperation and } \\
\text { contribution of } \\
\text { beneficiaries }\end{array}$ \\
\hline $\begin{array}{l}\text { The features of } \\
\text { clinical } \\
\text { guidelines: } \\
\text { L1-L8 }\end{array}$ & $\begin{array}{l}\text { The potential of } \\
\text { localizing the } \\
\text { guidelines in the } \\
\text { country }\end{array}$ & $\begin{array}{l}\text { Implementability of } \\
\text { guidelines across all } \\
\text { patients }\end{array}$ & $\begin{array}{l}\text { Practicalizing } \\
\text { guidelines }\end{array}$ & $\begin{array}{l}\text { Convenience in } \\
\text { implementing clinical } \\
\text { guidelines }\end{array}$ & $\begin{array}{c}\text { Access to } \\
\text { higher-quality evidence }\end{array}$ & $\begin{array}{l}\text { Sufficient production and } \\
\text { publication in the number } \\
\text { and distribution of clini- } \\
\text { cal guidelines }\end{array}$ & $\begin{array}{l}\text { Availability of a clear } \\
\text { protocol for production } \\
\text { and adaptation }\end{array}$ & $\begin{array}{l}\text { Resolving the } \\
\text { ambiguity of } \\
\text { clinical } \\
\text { guidelines }\end{array}$ & \\
\hline $\begin{array}{l}\text { Organizational } \\
\text { culture: } \\
\text { F1-F8 }\end{array}$ & $\begin{array}{l}\text { Corresponding to } \\
\text { patient needs }\end{array}$ & $\begin{array}{l}\text { Interaction between } \\
\text { physician and patient }\end{array}$ & $\begin{array}{l}\text { Adequate notification } \\
\text { to the patient }\end{array}$ & $\begin{array}{l}\text { Developing collabora- } \\
\text { tion and commitment } \\
\text { for following up the } \\
\text { course of treatment by } \\
\text { the patient }\end{array}$ & $\begin{array}{l}\text { Taking the patient } \\
\text { preferences into account }\end{array}$ & $\begin{array}{l}\text { Correspondence with } \\
\text { previous experiences of } \\
\text { using guidelines }\end{array}$ & $\begin{array}{l}\text { Understanding the patient } \\
\text { need to guidelines and } \\
\text { patient adaptation }\end{array}$ & $\begin{array}{l}\text { Physician } \\
\text { understanding, } \\
\text { generalizing the } \\
\text { research findings to } \\
\text { the patient } \\
\text { population }\end{array}$ & \\
\hline
\end{tabular}

4 http://mirii.iums.ac.ir

Med J Islam Repub Iran. 2020 (16 Sep); 34.122. 


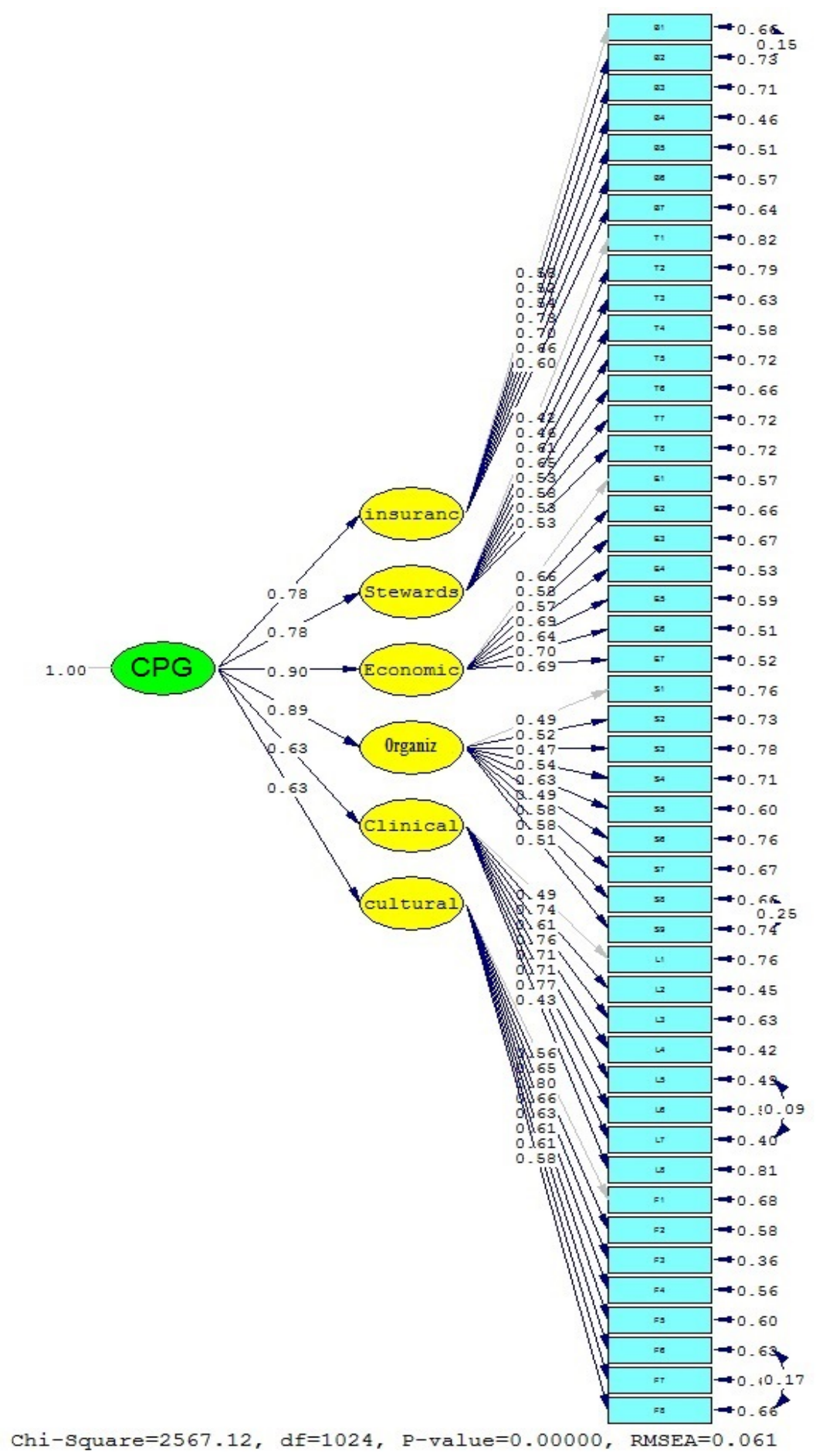

Fig. 1. General structure of the confirmatory factor analysis in standardized coefficient state

To analyze the confirmed factor, the data and the studied responses were used according to the proposed structure. The results of goodness-of-fit indices for the model are presented in Figure 1, suggesting approval of the studied index. Also, the value of the approximate error of the approximation variance (RMSEA) was equal to 0.61. Also, the adaptive fitness index (CFI), the fitness index (GFI), the incremental fitness index (IFI), and the normal fitness index (NFI) were all good, so the fit model was good and confirmed (Table 3 ).

In general, and considering the calculated indices, goodness-of-fit of the model can be concluded. With loading factors, the economic dimension had the maximum effect on implementing clinical guidelines (0.90), while the clinical guidelines feature (0.63) and organizational culture $(0.63)$ showed the minimum extent of effect on implementing clinical guidelines. 
Table 3. Indicators of confirmatory factor analysis model

\begin{tabular}{lllllll}
\hline $\mathrm{IFI}>0.9$ & CFI $>0.9$ & GFI $<0.8$ & NFI $>0.9$ & RMSEA $<0.08$ & x $2 / \mathrm{df}<3$ \\
\hline 0.95 & 0.95 & 0.79 & 0.92 & 0.061 & 2.50 \\
\hline
\end{tabular}

\section{Discussion}

The present study aimed to identify the most important effective factors on creating a system for developing and implementing clinical guidelines and the loading value of each factor on the principal components in the context of Iran. Clinical performance guidelines (CPGs) are considered as one of the knowledge products that aim to improve clinical services, help in decision-making for physicians and patients, function as a means for insurance with the aim of controlling the costs, and help governments in policymaking or prioritizing health care $(28,29)$.

Six groups of the influential factors were identified after analysis, some of which have also been mentioned in other frameworks and models. For example, in coordinated implementation model, the most important factors were organizational setting, education, economic factors, social, and administrative factors and eventually the personal environment of individuals, and the role of information, motivation, existence of regulations, and patient conditions (30). Furthermore, Thorsen mentioned some factors, such as knowledge, attitude, and skills of the patient and physician and organizational and economic factors, as the obstacles against implementing guidelines. In this study the effect of support of managers, thought of leaders, professionality of individuals, organizational efficiency, the characteristic of colleague groups, and other service providers have been mentioned (31). In another model which also propounds the clinical performance setting, a combination of economic, organizational, cultural, and policymaking effects has been mentioned as influential factors. In addition, this model emphasizes the effect of the ability of implementation, awareness, and attitude of physicians (20). Financial interventions in the present study referred to disciplinary and motivational interventions. Generally, financial interventions focus on service providers or patients (32). As long as financial incentives and the payment system are not corrected, adhering to clinical guidelines cannot be expected (14).

Other studies have included the following barriers to the implementation of clinical guidelines:

1. Knowledge, attitude, and behavior change of patients and physicians (20);

2. Characteristics of clinical guidance, including ambiguity and simplicity (32);

3. Environmental factors, such as lack of time, lack of sufficient resources, and payment system problems.

Furthermore, in other relevant studies, the most common obstacles against implementation of guidelines in the health care system have been mentioned as research obstacles, limited support of colleagues, and obstacles of change $(33,34)$. Poor communication, deficiency of technical abilities of policymakers, limited capacity for conducting clinical research, constraint of resources, legal processes, infrastructures, equipment, and the recognized market, and resolving the budget constraints, lack of valid support for altering the leadership, and diminished leadership power were also mentioned as the main obstacles against implementing guidelines $(8,16,35-38)$. In addition, such factors as presence of contradictory instructions and environmental factors, including lack of time, refund system (8), organizational constraints, and the increased understanding of the need to implement clinical guidelines, have been mentioned as obstacles against implementing clinical guidelines (39).

Absence of an evidence-based health care system has been one of the main reasons behind the attempts of economic development of evidence-based practice (EBP) over the past decade in Iran (40). Indeed, absence of an evidence-based health care system and improper political support on macro scale in Iran as a developing country have challenged the creation of a system for developing and implementing clinical performance guidelines (CPG) (41). Studies conducted in Iran on the awareness and attitude of physicians about CPG have suggested inadequate familiarity of physicians as the most important factor in failure to implement clinical guidelines $(24,42,43)$.

Inadequate production and publication of CPGs might be one of the reasons of the unfamiliarity with CPG by physicians. In a study, most physicians stated they had access to a limited number of CPGs and used them in their clinical practice. The findings of a study in the US indicated over half of physicians have changed their clinical methods based on CPG, while 3\% did not use it in their practice (44). Successful implementation of the guidelines involves development, publication, and implementation (9). The organizations involved in production of guidelines should develop the strategies for publicizing guidelines for timely delivery of information, reducing the complexity of clinical guidelines for physicians, and producing simple and understandable clinical guidelines (45). In qualitative studies conducted on the influential factors on implementing clinical guidelines, the factors were found to be approving the subject and content, approving the references, organizational factors, patient characteristics, and the strategies of publication of journals (33). A supportive organizational culture can act as a catalyst for EBP implementation with respective factors, including available information, abundant sources for developing change, and skillful personnel to change the practice, having prerequisite skills, and powerful leadership (46).

Therefore, the results of the present study and those of similar studies suggest that along with the trend of corresponding and developing CPG, planning should also be done for their implementation. The mentioned interventions have been implemented with the following final goals:

- Make sustainable behavior change in health care providers;

- Involve all service providers; 
- Provide appropriate facilities for the implementation of evidence-based clinical guidelines in health care centers;

- Time management;

- Human resources management;

- Provide training to properly search for clinical guides;

- Create the necessary infrastructure;

- Have adequate planning, supervision, and guidance;

- Create professional and legal motivation.

\section{Conclusion}

Evidently, promoting the mentioned interventions with the ultimate goal of sustainable behavior change in providing health care services requires the following steps: contribution of all practitioners and health service providers, presentation of suitable facilities for implementing clinical guidelines based on evidence, time and personnel management, training methodology and planning, development of the necessary infrastructure, supervision, and development of professional and legal motivation.

\section{Acknowledgement}

This work was extracted from a PhD thesis. The authors would like to thank all who cooperated in this study, including the heads and employees of Ministry of Health and Medical Education.

\section{Conflict of Interests}

The authors declare that they have no competing interests.

\section{References}

1. Graham ID, Logan J, Harrison MB, Straus SE, Tetroe J, Caswell W, et al. Lost in knowledge translation: time for a map? J Contin Educ Health Prof. 2006;26:13-24.

2. Straus SE, Richardson WS, Glasziou P, Haynes RB. Evidence based medicine: how to practice and teach it. Edinburgh (UK): Elsevier; 2005.

3. Kitson A, Straus SE. The knowledge-to-action cycle: identifying the gaps. CMAJ. 2010;182(2):E73-E77.

4. Hajebrahimi S, Sadeghi-Ghyassi F, Olfati N, Dastgiri S, Maghbouli L. Evidence based practice: perspectives of Iranian urologists. Urol J. 2014;10(4):1099-105.

5. Dalrymple PW, Lehmann HP, Roderer NK, Streiff MB. Applying evidence in practice: a qualitative case study of the factors affecting residents' decisions. Health Inform J. 2010;16(3):177-88.

6. Grol R, Wensing M, Eccles M. Improving patient care: the implementation of change in clinical practice. Elsevier Butterworth Heinemann Edinburgh. 2005.

7. Kashyap N, Dixon J, Michel G, Brandt C, Shiffman R. GuideLine implementability appraisal v. 2.0. In Book: GuideLine implementability appraisal v. 2.0 Yale Center for Medical Informatics, New Haven; CT. 2011.

8. Forsner T, Hansson J, Brommels M, Wistedt AA, Forsell Y.Implementing clinical guidelines in psychiatry: A qualitative study of perceived facilitators and barriers. BMC Psychiatry. 2010;10(8):110.

9. Fischer F, Lange K, Klose K, Greiner W, Kraemer A. Barriers and Strategies in Guideline Implementation-A Scoping Review. Healthcare .2016; 4(36):1-16.

10. Bero L. Barriers and facilitators to the implementation of clinical practice guidelines: a cross-sectional survey among physicians in Estonia. BMC Health Serv Res. 2012;12(455):1-7.

11. Yang J, Han C, Yoon HK, Pae C, Kim MJ, Park SY, et al. Experi- ences and barriers to implementation of clinical practice guideline for depression in Korea. BMC Psychiatry. 2013;13(150):1-14

12. Fretheim A, Schunemann HJ, Oxman AD. Improving the use of research evidence in guideline development: 5. Group processes. Health Res Policy Syst. 2006;4:17.

13. Van Dulmen SA, Maas M, Staal B, Rutten G, Kiers H, Nijhuis-van der Sanden M, et al. Effectiveness of peer assessment for implementing a dutch physical therapy low back pain guideline: A cluster randomized controlled trial. Phys Ther. 2014;94(10):1396-1409.

14. Majdzadeh R, Baradaran- Seyed Z. How to Implement Clinical Practice Guidelines in Iran. Iran Red Crescent Med J. 2013;15(11):e9702.

15. Kimiaeimehr F, Hosseini SM, Alimohammadzadeh K, Bahadori M, Maher A. The study of factors affecting the implementation of clinical guidelines in Iran. J Mil Med. 2019;21(3):300-310.

16. Francke A, Smit M, de Veer A, Mistiaen P. Factors influencing the implementation of clinical guidelines for health care professionals: a systematic meta-review. BMC Med Inform Decis Mak. 2008;8(1):38.

17. Leach MJ, Gillham D. Are complementary medicine practitioners implementing evidence based practice.?Complement Ther Med. 2011;19(3):128-36.

18. Storm-Versloot MN, Knops AM, Ubbink DT, Goossens A, Legemate DA, Vermeulen H. Long-term adherence to a local guideline on postoperative body temperature measurement: Mixed methods. Analys J Eval Clin Pract. 2012;18(4):841-847.

19. Wolpert C, Lubinski A, Bissinger A, Merkely B, Priori S, Brugada J. Barriers to implementation of evidence-based electrical therapies and the need for outcome research: role of European registries. Europace. 2011;13:II18- II20

20. Baradaran-Seyed Z, Nedjat S, Majdzadeh R. Barriers of Clinical Practice Guidelines Development and Implementation in Developing Countries: A Case Study in Iran, Int J Prev Med. 2013;4(3):340-8

21. Mounesan L, Nedjat S, Majdzadeh R, Rashidian A, Gholami J. Only One Third of Tehran's Physicians are Familiar with 'Evidence-Based Clinical Guidelines'. Int J Prev Med. 2013;4(3):349-57.

22. Mozafarpour S, Sadeghizadeh A, Kabiri P, Taheri H, Attaei M, Khalighinezhad N. Evidence-based medical practice in developing countries: The case study of Iran. J Eval Clin Pract. 2011;17:651-6.

23. Luitjes SH, Wouters MG, Franx A, Scheepers HC, Coupe VM, Wollersheim $\mathrm{H}$, et al .Study protocol: Cost effectiveness of two strategies to implement the NVOG guidelines on hypertension in pregnancy: An innovative strategy including a computerised decision support system compared to a common strategy of professional audit and feedback,a randomized controlled trial. Implem Sci. 2010;5:68

24. Ebadifard Azar F, Rezapour A, Mousavi Isfahani H, Azami-Aghdash S, Kalavani Kh, Mahmoudi F. Evidence- based medicine performance among health care providers in Iranian hospitals: A nationwide survey. Med J Islam Repub Iran. 2017 (12 Dec);31:77.

25. Gagliardi AR, Brouwers MC, Palda VA, Lemieux-Charles L, Grimshaw J. How can we improve guideline use. A conceptual framework of implementability? Implem Sci. 2011;6: 26.

26. Lugtenberg M, Zegers-van Schaick J, Westert G, Burgers J. Why don't physicians adhere to guideline recommendations in practice? An analysis of barriers among Dutch general practitioners. Implem Sci. 2009;4(54).

27. Rashiner T, Hansson J,Brommels M, Wistedt AA, Forsell Y. Implementing clinical guidelines in psychiatry: A qualitative study of perceived facilitators and barriers. BMC Psychiatry. 2010;10(8):1-10.

28. Habibi A, Adanvar M. Structural Equation Modeling and Factor Analysis.5th ed. Tehran: Academic Jihad; 2017.

29. Taba P, Rosenthal M, Habicht J, Tarien H, Mathiesen M, Hill S, Bero L. Barriers and facilitators to the implementation of clinical practice guidelines: A cross-sectional survey among physicians in Estonia. BMC Health Serv Res. 2012;12:455.

30. Cabana MD, Rand CS, Powe NR, Wu AW, Wilson MH, Abboud PA, et al. Why don't physicians follow clinical practice guidelines. A framework for improvement? JAMA. 1999;282(15):1458-65.

31. Thorsen T, Mäkelä M. Changing professional practice: theory and practice of clinical guidelines implementation: DSI Danish Institute for Health Services Research and Development; 1999.

32. Bayer G. Clinical practice guidelines: what are they and how should they be disseminated? Hand Clin. 2014;30(3):361-5.

33. Rashidian A, Yousefi-Nooraie R. Development of a Farsi translation of the AGREE instrument, and the effects of group discussion on improving the reliability of the scores. J Eval Clin Pract. 2012;18:67681. 
34. Sadeghi-Bazargani H, Tabrizi JS, Azami-Aghdash S. Barriers to evidence-based medicine: a systematic review. J Eval Clin Pract. 2014;20(6):793-802.

35. Hyder AC, Corluka A, Winch P, El-Shinnawy A, Ghassany H, Malekafzali $\mathrm{H}$, et al. National policy-makers speak out: are researchers giving them what they need? Health Policy Plan. 2011;26:73-82.

36. Oxman AD, Fretheim A, Schunemann HJ. Improving the use of research evidence in guideline development: introduction. Health Res Policy Syst. 2006;4:12.

37. McKillop A, Crisp J, Walsh K. Barriers and enablers to implementation of a New Zealand-wide guideline for assessment and management of cardiovascular risk in primary health care: a template analysis. Worldviews Evid Based Nurs. 2012;9(3):159-71

38. Rycroft-Malone J, Bucknall T. Models and frameworks for implementing evidence-based practice: Linking evidence to action. Oxford: Wiley-Blackwell. 2010.

39. Almazrou Mazrou SH. Expected benefits of clinical practice guidelines: Factors affecting their adherence and methods of implementation and dissemination. J Health Spec. 2013;1(3):141-7.

40. Baradaran-Seyed Z, Majdzadeh R. Evidence-based health care, past deeds at a glance, challenges and the future prospects in Iran. Iran J Publ Health. 2012;41(12):1-7.

41. Majdzadeh R, Yazdizadeh B, Nedjat S, Gholami J, Ahghari S. Strengthening evidence-based decision-making: is it possible without improving health system stewardship? Health Policy Plan. 2012;27:499-504.

42. Ahmadi-Abhari S, Soltani A, Hosseinpanah F. Knowledge and attitudes of trainee physicians regarding evidence-based medicine: a questionnaire survey in Tehran, Iran. J Eval Clin Pract. 2008;14(5):775-9.

43. Ghojazadeh M, Azami-Aghdash S, Pournaghi Azar F, Fardid M, Mohhseni M, Tahamtani T. A systematic review on barriers, facilities, knowledge and attitude toward evidence-based medicine in Iran. J Anal Res Clin Med. 2015;3(1):1-11.

44. Wolfe RM, Sharp LK, Wang RM. Family physicians' opinions and attitudes to three clinical practice guidelines. J Am Board Fam Pract. 2004; 17:150-7.

45. Spallek H, Song M, Polk D. E, Bekhuis T, Frantsve-Hawley J. Aravamudhan $\mathrm{K}$. Barriers to implementing evidence-based clinical guidelines: a survey of early adopters. J Evid Based Dent Pract. 2010;10(4):195-206.

46. Kueny N, Shever L, Lehan Mackin M, G Titler M. Facilitating the implementation of evidence-based practice through contextual support and nursing leadership. J Healthc Leadersh. 2015;7:29-39. 